\title{
COMBINED TITRI METRIC AND POLARI METRIC METHODS FOR DETERMINATION OF MALTOSE IN MALTING BARLEY
}

\author{
KERI ALHADI IGHWELA ${ }^{1}$, AZIZ BIN AHMAD ${ }^{2}$, ABDULLAH MD ZAIN ${ }^{3}$ and A.B. \\ ABOL-MUNAFI ${ }^{1}$ \\ 1. Institute of Tropical Aquaculture, Universiti Malaysia Terengganu, Malaysia. \\ 2. Department of Biology, Faculty of Science, Universiti Malaysia Terengganu, Malaysia. \\ 3. Department Agro Ttechnology, Faculty of Agro Technology and Food Science, Universiti Malaysia Terengganu.
}

\begin{abstract}
This method was developed for the determination of maltose in malting barley and other cereals, and in certain products containing malted barley. Using a modification of the procedure originally described by Bates and co-workers (1942), which determined sugar in sugar solution by the polarimeter. In this study combined titration and Polari metric quantification as described by Bates was modified. Malt samples were prepared by extraction for barley seeds by germination method. The malt content of the hydrolyzed maltose was quantified. Preparation of the extract that was commonly used for titration method should be sensitive response and sensitivity for sugar in malt. In this case, good agreements were obtained between this method and commonly used methods based on chemical maltose determination, such as titration method.
\end{abstract}

Key words: Combined, Titri metric, Polari metric, determination, maltose, malting barley.

\section{Introduction}

Methods in malted barley quality determination are important in assessing malting barley quality. Determination of the quality of product and have significant position in the food industry, and nutrition is necessary for the point of product features and economic view. However, choosing the appropriate method of determination of maltose in malt is very important to produce products such as bread, biscuit, etc. To addition the method analyzing or to determine malt quality must be appreciated exacting. Several methods are available for determining the maltose, such as titration, polarimeter, Benedict and enzymatic hydrolysis, which are widely employed in the food industries (AOAC, 1990). Determination of maltose is a routine analysis, especially in malt manufacture. The usual method is the titration of total reducing sugars such as maltose (Ge et al, 1998). We selected titration for the reference method, but we used to preparation of extract a sample, instead of maltose solution which known concentration, used in polarimeter method. Therefore, the main objective of this study was to develop polarimeter method to determine of maltose in malting barley to achieve a method with good performance in terms of accuracy-precision, easy-handling and simultaneous quick determination.

\section{Experimental / Methodology}

Samples and Reagents

Malting barley was prepared by extraction of barley seeds were purchased at Libyan a local market. The reagents (Acetate Buffer solution, sodium tungstate solution) were prepared in analytical Lab of chemistry department, Faculty of Science and Technology, University Malaysia Terengganu (UMT), Malaysia.

\section{Equipments and Apparatus}

An analytical balance (Sartorius), a water bath (Memmert), Polarimeter (Polax-2L). Filter paper (What man No. 4 or Equiv.).

\section{Preparation of extract and solution sample}

$5.675 \mathrm{~g}$ flour was placed in 100 or $125 \mathrm{~mL}$ Erlenmeyer. The flask was tilted to ensue so that all flour is at one side. The flour was wetted with $5 \mathrm{~mL}$ Alcohol (40\%). The flask was so that wet flour is at the upper side before adding $50.0 \mathrm{~mL}$ acetate buffer solution, keeping solution from coming in contact with flour until all is added to the flask. Then, flask was shaking to bring flour into suspension. Two $\mathrm{mL}$ Na tungstate solution was added immediately and mix thoroly the suspension was filtered immediately (Whatman No. 4, or equiv.). The first 8-10 drops of filtrate was discarded (AOAC, 1990). Then, Sample was prepared according to the modified methods of Williamson et al. (2003). $25 \mathrm{ml}$ sample solution was transferred to the volumetric flask $(50 \mathrm{ml})$, and made up to $50 \mathrm{ml}$ with de-ionized water. Obtain the aobs by analyzing solution in the polarimeter and calculated the specific rotation $[\alpha]$ by equation 


$$
\% \text { Sugar }=\frac{[\propto] \text { obs } \times 100}{1 \times[\propto]_{D}^{20}}
$$

The data were getting from both methods subjected to analysis of t-test to determined the different between the methods by using Gen stat 5 program,

\section{Results and Discussion}

Based on the experiments and modifications, the sugar concentrations were calculated with the Titrimetric and polar metric methods, the results observed that concentration of maltose was $72.26 \%$ and $74.51 \%$ by using polar metric and Titrimetric respectively without any significant different at 0.01 between the methods. This result is agreement with Titrimetric method. The results indicate a rapid, easy and low costly in determination of maltose in malting barley. Therefore, an experimental design was performed to improve the maltose determination in malted barley by modifying, the changes in preparation of solution sample. In both cases, good agreement was obtained between this method and usually used methods based on chemical methods. Good agreement between these methods was also found in the analysis of malted from several barley.

\section{Conclusion}

The presented method allows for measurements of the content of maltose in malting barley. The method is quick, easy and reliable. However, in the analyses of the barley flour needs to be precipitated using preparation of extract. The study showed that concentration of maltose was $72.26 \%$. The conditions to perform the maltose analysis need to be adjusted relative to previously published standard conditions.

\section{References}

1. AOAC, (1990): "Official methods of analysis. $15^{\mathrm{h}}$ ed. Association of Official Analytical" Chemists, Washington, D.C.

2. Bates F. J. and co-workers (1942) "Polarimetry, Saccharimetry and the Sugars, Circular C440, National Bureau of Standards U.S" . Government Printing Office, Washington, D.C., 1942.

3. Ge et al (1998) "Simultaneous determination of maltose and glucose using a screen printed electrode system"

4. Williamson K. (2003) "Macroscale and Microscale Organic Experiments, 4th edition", Houghton Mifflin, Boston. 